\title{
K-Drama dan Penyebaran Korean Wave di Indonesia
}

\author{
Idola Perdini Putri ${ }^{1}$, Farah Dhiba Putri Liany ${ }^{2}$, dan Reni Nuraeni ${ }^{3}$ \\ 1,2,3Program Studi Ilmu Komunikasi, Fakultas Komunikasi dan Bisnis, \\ Universitas Telkom, Bandung
}

\begin{abstract}
ABSTRAK
Korean wave adalah istilah yang diberikan untuk penyebaran budaya populer Korea melalui produkproduk hiburan seperti drama, musik, style. Keberadaan Korean wave di Indonesia menjadi fenomena yang menarik untuk diteliti. Penelitian ini membahas tentang peranan kebudayaan populer Korea, Korean Drama (K-Drama) dalam fenomena Korean wave yang terjadi di Indonesia. Drama Korea atau K-Drama menjadi awal kemunculan dari Korean wave di Indonesia. Penggunaan metode kualitatif dengan pendekatan historis pada penelitian ini, bertujuan untuk dapat merekonstruksi K-Drama yang muncul di Indonesia, khususnya di Stasiun TV Indosiar dari tahun 2002 hingga tahun 2013. Melalui analisis data-data serial TV Korea yang tayang di Indonesia, penelitian ini menjelaskan tentang perkembangan $K$-Drama sebagai pemicu dari munculnya Korean wave, perkembangan $K$-Drama di Indonesia, hingga dampak yang ditimbulkan dari K-Drama seperti kemunculan eksistensi produk budaya pop Korea lainnya, yaitu K-Pop dan K-Style di Indonesia. K-Drama memiliki peranan yang cukup penting atas Korean wave di Indonesia. Di mana hal-hal tersebut dapat terlihat pada dampak K-Drama di Indonesia, seperti kemunculan komunitas-komunitas pecinta K-Drama, hadirnya situs dari Indonesia yang menyajikan informasi seputar Korea, bahkan hingga maraknya acara-acara yang mengundang aktor, penyanyi, idola-idola Korea ke Indonesia. Korean Wave sendiri menjadi soft power Korea Selatan melalui budaya populernya yang diekspor ke berbagai negara dalam bentuk K-Drama, K-Pop, $K$-Style, kuliner dan teknologi. Melalui nilai-nilai yang terdapat dalam pembuatan budaya populer, terutama drama, Korea memadukan unsur modern dalam hal ini teknologi dengan tradisi dan nilai-nilai kekeluargaan. Korean wave di Indonesia sendiri ditandai dengan maraknya kemunculan kuliner khas Korea, sinetron adaptasi cerita $K$-Drama, fashion khas Korea, hingga tujuan wisata tempat pembuatan K-Drama.
\end{abstract}

Kata-kata Kunci: Korean wave; k-drama; kebudayaan populer Korea; style; Indonesia

\section{K-Drama and Korean Wave Diffusion in Indonesia}

\section{ABSTRACT}

Korean wave is a term given to the spread of Korean popular culture through entertainment products such as drama, music, and fashion. The existence of the Korean wave in Indonesia has become an interesting phenomenon to study. This study discusses the role of Korean popular culture, Korean Drama (K-Drama) in the Korean wave phenomenon that occurred in Indonesia. Korean Drama or K-Drama is the beginning of the emergence of the Korean wave in Indonesia. The use of qualitative methods with a historical approach in this study aims to reconstruct K-Drama that emerged in Indonesia, especially in Indosiar from 2002 to 2013. Through the analysis of data from Korean TV series that aired in Indonesia, this study explains about the development of K-Drama as a trigger of the emergence of the Korean wave, the development of K-Drama in Indonesia, to the impact of K-Drama such as the emergence of the existence of other Korean pop culture products, namely K-Pop and K-Style in Indonesia. K-Drama has an important role in the Korean wave in Indonesia. Where these things can be seen in the impact of K-Drama in Indonesia, such as the emergence of K-Drama lovers communities, the presence of sites from Indonesia that provide information about Korea, even to the rise of events that invite actors, singers, idols Korean idol to Indonesia. The Korean Wave itself became South Korea's soft power through its popular culture which was exported to various countries in the form of K-Drama, K-Pop, K-Style, culinary and technology. Through the values contained in the making of popular culture, especially drama, Korea combines modern elements in this case technology with tradition and family values. The Korean wave in Indonesia itself is marked by the rise of Korean cuisine, soap opera adaptations of K-Drama stories, Korean fashion, and tourist destinations for K-Drama production.

Keywords: Korean wave; $k$-drama; korean popular culture; style; Indonesia

Korespondensi: Idola Perdini Putri. Universitas Telkom. Jl.Telekomunikasi No.01, Terusan Buah Batu, Sukapura, Dayeuhkolot, Bandung, Jawa Barat 40257.Email: idolaperdiniputri@telkomuniversity.ac.id 


\section{PENDAHULUAN}

Hallyu atau Korean wave adalah istilah yang diberikan untuk budaya pop Korea Selatan yang tersebar secara global di berbagai negara di dunia, termasuk di Indonesia (Shim, 2006). Korean wave memang telah dipersiapkan untuk dipasarkan ke dunia internasional sejalan dengan adanya dukungan penuh dari Pemerintah sejak masa Pemerintahan Presiden Kim Dae Jung (1993-1998) yang slogan politiknya adalah "Creation of the New Korea". Dengan kata lain, Pemerintah Korea ingin menghapus citra bangsa yang tradisional dan membuat citra nasional yang lebih baru dan modern. Kebijakan budaya di masa Pemerintahan Kim Dae Jung dimaksudkan untuk membangun identitas budaya dari perspektif internasional dan untuk membangun kreatifitas budaya suatu bangsa sehingga mantan Presiden Kim dikenal sebagai "President of Culture". Lalu, pada awal tahun 2000-an, setelah krisis finansial yang melanda kawasan Asia di tahun 1997, Pemerintah Korea mulai menargetkan ekspor budaya populer Korea sebagai bentuk inisiatif pelaksanaan sektor perekonomian baru. Mantan Presiden Kim mendirikan Basic Law for the Cultural Industry Promotion pada tahun 1999 dengan mengalokasikan dana senilali US\$148.5 juta untuk mengembangkan dan menyebarluaskan budaya popular Korea melalui cara-cara inovatif dengan menggabungkan budaya tradisional mereka dengan budaya modern.

Jika menyinggung tentang Korean wave, maka hal yang sering diketahui orang ialah K-Pop. K-Pop merupakan sebutan untuk musik pop Korea, secara harafiah merupakan kepanjangan dari Korean Pop. K-Pop menjadi budaya populer yang digunakan oleh Korea Selatan bukan sekedar dari musiknya saja, namun tarian yang dilakukan dari setiap penyanyi di Korea Selatan menjadi "selling point" tersendiri. Karena memang tujuan dari K-Pop juga sebagai invasi budaya, maka agensi musik di Korea mengadakan audisi untuk sebagai penyanyi K-Pop dari negara lain seperti Amerika, Kanada, China, Jepang, Thailand (Department Global Communication and Contents Division, 2012).

Di Indonesia sendiri, penyebaran budaya pop dari Korea dimulai sejak tahun 2002 setelah Piala Dunia Korea Selatan dan Jepang. Momen tersebut yang diselenggarakan di stasiun televisi Indonesia, kemudian digunakan untuk memperkenalkan drama seri Korea Selatan atau K-Drama. Trans TV menjadi stasiun televisi pertama yang menayangkan $K$-Drama berjudul Mother's Sea pada 26 Maret 2002. Lalu menyusul Indosiar dengan Endless Love pada 1 Juli 2002. Tercatat terdapat sekitar 50 judul drama Korea yang tayang di stasiun TV swasta Indonesia pada tahun 2011 dan terus meningkat 
setiap tahunnya.

Berdasarkan survei AGB Nielsen Indonesia di Kompas Online 14 Juli 2003, drama Endless Love yang ditayangkan di televisi Indosiar pada tahun 2002 berhasil mendapatkan rating 10 . Perolehan rating tersebut berarti drama tersebut ditonton oleh sekitar 2,8 juta orang di lima kota besar di Indonesia. Drama ini menjadi bukti nyata bahwa drama seri dari negeri gingseng ini mendapatkan perhatian yang cukup di Indonesia (Nugroho, 2011).

Drama seri Korea muncul pada tahun 2002, tidak begitu saja menghilangkan drama Jepang yang biasa disebut dorama. Dorama yang berjudul Itazura $\mathrm{Na}$ Kiss pada tahun 2004 juga menarik perhatian. Para penggemar dorama tidak langsung melupakan dorama dan beralih sepenuhnya kepada drama Korea. Pada 2011, Indosiar menayangkan drama Korea yang mengadaptasi dorama Jepang Itazura $\mathrm{Na}$ Kiss tersebut, dengan judul Playful Kiss. Serial Meteor Garden yang berasal dari Taiwan pun juga ditayangkan di televisi Indonesia pada 2002. Para pemirsa di Indonesia sebelumnya memang sudah terbiasa menyaksikan produk-produk asia seperti Kung Fu dan aksi laga Hong Kong. Ketika Meteor Garden muncul, para pemirsa bisa lebih menerima. Apalagi disuguhkan oleh cerita yang memiliki konten hampir seluruhnya kisah percintaan, persahabatan, dan perjuangan di kota metropolitan Asia. Kesuksesan drama seri Taiwan ini pun kembali tercatat pada drama seri Korea yang mengadaptasi dari drama seri Taiwan Meteor Garden, dengan judul Boys Before Flower. Di tahun yang sama dengan penayangan Meteor Garden, setelahnya Indosiar menayangka Endless Love, drama Korea yang menjadi awal dari pengenalan K-Drama di Indonesia. Drama seri Korea inilah yang menjadi seperti awal dari popularitas drama Korea di televisi Indonesia, khususnya Indosiar. Kemudian tayang Mother's Sea Trans TV meskipun tidak sesukses Winter Sonata yang muncul di stasiun televisi Indosiar pada Juli 2002 dan memperoleh rating 11 persen sejak awal ditayangkan. Hingga kini, rating merupakan alasan utama ditayangkannya sebuah program. Rating tinggi dianggap berbanding lurus dengan kesuksesan menjaring iklan (Gemiharto, Abdullah, \& Puspitasari, 2017).

Sejak saat itu, Korean wave mulai menyebar di Indonesia melalui K-Drama. Lebih dari 50 drama seri Korea Selatan ditayangkan di stasiun televisi di Indonesia, dan dari sekian K-Drama yang ditayangkan di Indosiar, yang memperoleh rating tinggi ialah dari drama seri Full House yang mencapai rating mendekati 40 persen saat ditayangkan di tahun 2005 (Chung, 2011).

Drama seri Korea Selatan memberikan perkembangan besar di Indonesia, seperti yang diberitakan dalam artikel di The Jakarta Post 
pada Juli 2011 berjudul Korean Wave Casts a Spell in Indonesia. Semenjak Winter Sonata meraih perhatian penonton di Indonesia, semenjak itu pula bermunculan drama seri Korea Selatan lainnya di televisi Indonesia. Semenjak munculnya Korean wave di Indonesia, hal tersebut memberikan pengaruh terhadap kemunculan komunitas Korea di Indonesia dengan hampir terdapat 50.000 orang yang tergabung.

Kehadiran K-Drama pun dapat membawa pengaruh tersendiri di pasar Indonesia, contohnya dengan menjadikan drama seri Korea Selatan sebagai acuan pembuatan sinetron. Selain itu juga menimbulkan kegemaran budaya populer lainnya, seperti adanya K-Pop, gaya berpakaian khas artis-artis Korea Selatan, make up, bahkan hingga munculnya tempat makan Korea Selatan, tempat kursus bahasa, bahkan toko-toko yang menjual pernak-pernik Korea Selatan.

Fenomena budaya populer dari Korea Selatan yang terjadi belakangan ini, menjadi alasan peneliti melakukan penelitian ini. Peneliti tertarik dengan kajian akan budaya populer Korea Selatan berupa K-Drama yang memberikan dampak dari eksistensi K-Drama tersebut di Indonesia. Penelitian mengkhususkan pada peranan K-Drama sebagai produk budaya populer Korea Selatan yang pada akhirnya mendukung persebaran budaya
Korea Selatan di Indonesia, serta menjadi salah satu alat diplomasi Korea di Indonesia. Fokus dari penelitian ini adalah menjawab bagaimana peran K-Drama sebagai produk budaya populer Korea Selatan dalam penyebaran Korean Wave pada penonton di Indonesia. Pada penelitian ini, peneliti juga melakukan pembatasan penelitian pada stasiun televisi Indosiar sebagai stasiun televisi yang dijadikan sumber informasi Pemilihan Indosiar sebagai stasiun televisinya, ialah karena Indosiar merupakan stasiun televisi yang konsisten menayangkan $K$-Drama sejak tahun 2002

\section{TINJAUAN PUSTAKA}

John Fiske berpendapat bahwa komoditas budaya seperti televisi tersebar dalam dua ekonomi sekaligus: ekonomi finansial dan ekonomi kultural. Ekonomi finansial terutama menaruh perhatian pada nilai tukar, sedangkan ekonomi kultural terutama berfokus pada nilai guna seperti makna, kesenangan dan identitas sosial (Storey, 2006). Dalam drama seri Korea, ketika drama tersebut disponsori oleh suatu perusahaan, maka audiens drama tersebut secara tidak langsung juga menjadi sasaran bagi produsen tersebut yang memungkinkan menjadi konsumen. Hal itu terjadi dalam ekonomi finansial. Sedangkan dalam ekonomi kultural, drama menjadi suatu produksi yang diambil makna, kesenangan, serta identitas sosial, oleh 
para penontonnya.

Drama Korea ber-genre action-adventure seperti Iris and Athena: Goddes of War menjadi drama yang menampilkan banyak adegan action seperti tampilan berbagai macam efek ledakan, tembak-menembak dan juga kejarmengejar mobil. Hal ini semakin menunjukan kemajuan teknologi dalam pembuatan drama di Korea Selatan. Pada era ini, garis besar cerita tidak lagi terkait hanya terhadap cerita kerajaan, perang, kehidupan di istana, namun jauh lebih bervariasi dan lebih bersifat imajinatif dan memadukan unsur-unsur petualangan. Seperti drama yang diproduksi oleh KBS, The Slave Hunters pada tahun 2010, yang merupakan action-adventure tentang budak yang kabur, pemburu, dan aristokrat yang gagal.

Menyadari bahwa drama seri Korea dapat menjadi cara memperkenalkan Korea, maka stasiun televisi memproduksi drama dengan mengemasnya dengan berbagai tujuan. Dana yang dibutuhkan untuk produksi drama dengan menggunakan teknologi berkembang tidaklah sedikit. Stasiun televisi memerlukan modal, dan para investor yang berasal dari pengiklan memanfaatkan drama seri Korea sebagai tempat untuk memasarkan produk-produk mereka. Karena itu banyak Produk-produk elektronik di Korea Selatan ditampilkan di drama. Dari keseluruhan drama seri Korea, stasiun-stasiun televisi di Korea Selatan menyadari bahwa genre yang disukai sehingga drama seri Korea Selatan dikenal di luar Korea sendiri ialah genre romance dan romantic comedy. Sejumlah film atau serial televisi yang sukses di pasaran sesungguhnya merupakan produk komunikatif yang bisa diterima oleh khalayaknya (Abdullah, Mahameruaji, \& Rosfiantika, 2018).

\section{METODE PENELITIAN}

Pendekatan penelitian ini menggunakan pendekatan kualitatif. Sementara, metode yang digunakan dalam penelitian ini ialah metode sejarah atau historis, dikarenakan data-data yang dibutuhkan untuk menyusun penelitian ini terdapat dari masa lampau atau hal yang sudah berlalu, sehingga metode historis digunakan merekonstruksi ulang penayangan K-Drama.

Peneliti menggunakan teori penerapan metode historis dari Sjamsuddin, yang mengatakan bahwa ada empat langakah dalam melakukan penelitian historis, yaitu: heuristik, kritik, interpretasi, dan historiografis (Sjamsuddin, 2007). Issac dan Michael menjelaskan bahwa metode historis bertujuan untuk merekontruksi kejadian secara sistematis dan objektif dengan mengumpulkan, menilai, memverifikasi, dan menyintesiskan bukti untuk menetapkan fakta dan mencapai konklusi yang dapat dipertahankan (Rakhmat, 2012).

Beberapa judul $K$-Drama yang ditayangkan pada stasiun televisi Indosiar sepanjang 
tahun 2002 hingga 2017 menjadi objek pada penelitian ini. Peneliti melakukan pemaparan berdasarkan kategorisasi yang muncul sesuai dengan drama populer yang ditayangkan di Indosiar. Teknik pengumpulan data primer yang dilakukan adalah studi dokumen (berupa film) dan wawancara informan sebagai data sekunder. Pada penelitian ini, peneliti mengunakan informan dari pihak Korean Cultural Centre Indonesia, juga budayawan kebudayaan Korea.

\section{HASIL DAN PEMBAHASAN}

Penelitian ini menunjukkan bahwa peran K-Drama sangat signifikan dalam mendorong penyebaran Korean Wave di Indonesia. Pada penelitian ini sendiri Korean Wave, dijelaskan sebagai hal-hal tentang Korea yang menjadi bagian dari budaya populer di Indonesia, seperti fashion, kuliner, teknologi, lokasi wisata, hingga akulturasi dengan budaya populer Indonesia.

Budaya-budaya yang ditimbulkan dari Korean wave yang memiliki asal usul dari K-Drama ini di Indonesia sudah semakin melekat. Seakan dengan mengimplementasikan hal-hal yang berkaitan dengan Korea merupakan kebanggan tersendiri, baik itu melalui bahasa, pakaian, makanan Korea yang dikonsumsi, hingga menjadikan Korea sebagai tujuan wisata. Image "ke-koreaan" sekarang sudah menjadi hal yang biasa di Indonesia. Keberlangsungan dari Korean wave di Indonesia yang muncul dari K-Drama ini tidak dapat diprediksi. Memang saat ini Korean wave belum mampu menggeser pola "kebarat-baratan" yang sudah mulai ditransmisi dan menggeser budaya Indonesia, namun tidak menutup kemungkinan jika Korean wave ini terus berkembang, dan istilah "ke-koreaan" dapat menjadi akulturasi budaya populer selanjutnya di Indonesia.

Drama seri Korea Selatan yang ditayangkan di televisi Indonesia berkembang sejak Piala Dunia 2002 yang diselenggarakan di Korea Selatan. Stasiun televisi memanfaatkan momentum tersebut sebagai saat untuk mengenalkan film dan drama seri Korea. K-Drama yang ditayangkan di stasiun televisi Indonesia juga secara sadar ataupun tidak mampu memengaruhi perilaku serta tindakan orang yang menontonnya.

Melalui K-Drama inilah kemunculan Korean wave di Indonesia mulai terasa, dengan semakin bermunculan komunitas-komunitas penyuka $K$-Drama, munculnya online shop yang menjual barang-barang Korea di Indonesia, hingga kepada sarana dibukanya pusat kebudayaan Korea (Korean Cultural Center Indonesia) dan juga universitas-universitas yang menyediakan program studi terkait Korea, lebih jauh, munculnya $K$-Pop dan $K$-Style.

Dampak lanjutan lain dari K-Drama sehingga berkembangnya Korean wave di 
Indonesia ialah dengan terlihatnya minat dan kemampuan untuk menonton konser bahkan fan-meeting yang diadakan oleh penyanyipenyanyi bahkan pemeran K-Drama di Indonesia. Production house di Indonesia sendiri menggunakan K-Drama sebagai ide untuk membuat sinetron, di mana terdapat sinetron-sinetron yang memiliki konsep cerita sama bahkan adegan sama dengan K-Drama.

K-Drama juga tidak hanya menjadi alat untuk melakukan marketing product bagi Korea Selatan, mulai dari budaya, makanan, bahasa, pariwisata, hingga teknologi. Kemajuan Korea dalam hal Korean wave yang dimulai melalui K-Drama ini tidak terlepas dari peran aktoraktor seperti pemerintah, media baik televisi maupun internet, industri produk budaya (drama televisi, musik, film, animasi dan games), industri produk komersial (seperti Samsung dan LG) serta publik-publik negara lain yang menjadi konsumen dari produk budaya Korea ini. Sarana terbesar sebagai sumber rujukan ialah datang dari media, sebagai sarana untuk memperoleh keuntungan perekonomian Korea Selatan yang sebenarnya bukan terletak pada produk budaya yang diekspor, namun lebih kepada pemanfaatan popularitas produk budaya populer Korea sebagai alat promosi suatu produk seperti produk komersial serta pariwisata.

Budaya dalam drama tersebut ditiru oleh penonton seperti gaya berpakaian, atau budaya lainnya. Tindak lanjutnya dapat mendatangkan perekonomian dari bidang budaya. Contohnya ialah budaya di Korea yang menghabiskan waktu saat kencan ke taman yang banyak pepohonan tinggi dan berjalan di tepi-tepi jalannya pada drama Winter Sonata. Budaya tersebut memengaruhi para penonton untuk mengunjungi lokasi tersebut saat ke Korea Selatan. Hingga paket-paket perjalanan ke Korea Selatan memasukan perjalanan ke lokasi-lokasi di drama Winter Sonata. Seperti disebutkan sebelumnya, kehadiran drama seri Korea Selatan ini membawa pengaruh tersendiri di pasar Indonesia, contohnya dengan menjadikan drama seri Korea Selatan sebagai acuan pembuatan sinetron serta memunculkan ketertarikan budaya populer lainnya, seperti K-Pop, style, make up, tempat makan Korea Selatan, tempat kursus bahasa, bahkan tokotoko yang menjual pernak-pernik Korea Selatan.

Jika melihat bagaimana $K$-Drama dapat memperoleh keberhasilan dalam menyebarkan Korean Wave, terdapat beberapa hal yang menjadi acuan. Pertama, drama Korea hadir di Indonesia pada waktu yang tepat, kedua K-Drama menyajikan sebuah cerita yang sangat mudah diterima oleh remaja di Indonesia, dan ketiga, serial televisi ini dengan menarik menggambarkan budaya Korea yang dikemas secara modern.

Kemunculan K-Drama di Indonesia karena 
adanya ketepatan tempat dan waktu. Ketika tayangan drama seperti dari Jepang dan China memiliki harga lumayan tinggi, Korea muncul dan menawarkan dramanya dengan harga yang relatif lebih murah dari dua negara tersebut. Selain itu, K-Drama menyajikan tema cerita yang masih menampilkan budaya-budaya Timur, ketika Jepang dan China sudah mulai condong ke arah kebarat-baratan. Alasanalasan ini bisa disebut bahwa $K$-Drama muncul pada saat dan waktu yang tepat, khususnya di Indonesia.

Stasiun televisi MBC menyiarkan drama seri berjudul Jewel in the Palace pada tahun 2003. Gaya dari drama seri ini cukup berbeda dari Winter Sonata. Jika setting waktu di Winter Sonata pada tahun 1998, maka Jewel in the Palace pada masa dinasti terakhir di Korea, yaitu dinasti Joseon (1392-1910). Perbedaan setting waktu pun menjadi hal yang signifikan terjadi, di mana pada drama seri Jewel in the Palace memberikan lebih banyak tampilan budaya tradisional Korea. Jewel in the Palace juga membuat prestasi lebih daripada Winter Sonata dengan berhasil menjual drama yang berjumlah 72 episode ini ke 87 negara pada Mei 2011

Popularitas drama seri Korea Selatan semakin bertambah semenjak video streaming di tahun 2000-an mulai banyak digunakan oleh orang-orang. Internet dimanfaatkan oleh stasiun-stasiun televisi di Korea Selatan untuk memfasilitasi orang-orang di luar Korea yang ingin menonton drama seri. Drama seri Korea Selatan dapat ditonton melalui online video seperti YouTube dan Hulu yang memberikan pengaruh. Pada 21 Juni 2011, stasiun televisi Korea MBC memberikan penayangan drama seri Naughty Kiss dalam special YouTube-only edition.

Antusiasme penonton terlihat dari kemunculan subtitle bahasa Inggris, China, Jepang dan Spanyol. Sedangkan melalui www. hulu.com, orang-orang Amerika Serikat dapat menyaksikan drama seri Korea yang mereka inginkan. Jika situs Hulu hanya bisa diakses server USA, maka ada situs yang dapat ditonton oleh negara-negara lain, seperti Drama Fever, Drama Crazy, Viki dan My Soju. Situs-situs ini memberikan terjemahan teks dalam berbagai macam bahasa, termasuk Indonesia. K-Drama tidak hanya lagi ditonton oleh orang Korea saja. Seluruh dunia terkena penyebaran dari Korean wave melalui K-Drama.

Membahas tentang K-Drama di Indonesia, maka Endless Love menjadi salah satu yang paling dikenal. Sebenarnya Endless Love bukanlah judul resminya. K-Drama yang disutradarai oleh Yoon Seok Ho dan diproduksi oleh KBS ini sebenarnya terdiri dari empat rangkaian drama yang berjudul dari musim, yaitu Autumn in My Heart (yang justru dikenal 
dengan Endless Love, Winter Sonata (Endless Love II), Summer Scent (Endless Love III), dan terakhir Spring Waltz (Endless Love IV). Keempat K-Drama ini merupakan proyek dari Sutradara Yoon Seok Ho yang ingin mempersembahkan empat cinta yang berbeda dari tiap musim.

Keempat drama yang memiliki outline dasar dari musim ini menjadi awal dari kemunculan K-Drama lainnya di luar Korea. Meskipun sebenarnya sejak tahun 60an Korea sudah memproduksi drama, tapi tidak bisa dihindari bahwa drama-drama dari Yoon Seok Ho ini sangatlah berpengaruh terhadap kemunculan Korean wave saat ini. Jika diambil benang merah dari keempat drama tersebut, $K$-Drama yang menjadi terkenal ini memiliki ide cerita Cinderella Story di dalamnya. Romantisme yang disuguhkan dalam K-Drama menjadi nilai jual tersendiri, dengan inti cerita yang sebenarnya bisa ditebak, di mana pemeran utama lebih banyak menonjolkan sisi perempuan yang berada di kalangan ekonomi bawah yang memiliki hubungan dengan pria dari kalangan atas. Ide inilah yang sebenarnya memunculkan image serta ciri khas tersendiri bagi K-Drama selanjutnya, sampai saat ini.

Selain itu, penonton K-Drama baik secara sadar maupun tidak sadar akan mengenal beberapa budaya serta kebiasaan orang Korea. Adapun hal-hal yang ditonjolkan seperti, memberi hormat dengan cara membungkuk, makanan khas Korea, adegan menggendong, bersepeda, melakukan apresiasi seni dalam keseharian (dalam hal ini budaya korea), minum minuman beralkohol, mengenal pakaian tradisional Korea (hanbok), hingga mengenal tulisan Korea (hangul).

Terlepas dari semua kekuatan K-Drama yang mampu memunculkan Korean wave, tanpa disadari Korea melakukan marketing product di dalam K-Drama. Di Korea terdapat istilah Chaebol atau yang berarti konglomerat. Chaebol membantu pemerintah dalam melakukan pengembangan terhadap industri, pasar dan juga ekspor baru. Jadi meskipun Chaebol ini ialah pihak swasta, tapi tidak ada oposisi dari negeri. Chaebol ini membuat Korea Selatan menjadi Newly Industrializing Economy (NIE) serta mampu menyetarakan diri dengan negara maju lainnya. Chaebol besar di Korea saat ini ialah Hyundai, Samsung, LG, Lotte, SK Group, Daewoo.

Dalam K-Drama seringkali ditemukan bahwa para pemain menggunakan produksi dari Chaebol tersebut. Seperti mobil yang menggunakan Hyundai, ponsel yang menggunakan Samsung atau LG. Jika banyak orang yang mengenal promosi produk melalui iklan, Korea lebih banyak memasarkan produk Chaebol melalui K-Drama.

Kemajuan teknologi Korea juga dapat 
dilihat melalui kesadaran mereka terhadap pemanfaatan media. Dalam hal ini ialah media online. Korea yang peka terhadap perkembangan teknologi menyadari bahwa Internet dapat dijadikan sebagai alat pemasaran yang cepat dan efektif, dalam hal ini ialah YouTube. YouTube menjadi sarana penyebaran khususnya ke wilayah Barat seperti Amerika dan Eropa. Dari penelitian Internet, jumlah akses video terkait dengan K-Pop di Youtube mencapai 123.47 juta di Amerika Utara dan 55,37 juta di Eropa dari total akses K-Pop 793.57 juta di seluruh dunia (Department Global Communication and Contents Division, 2012).

Tidak hanya itu, semakin terkenalnya K-Drama di luar Korea, maka semakin tekenal juga beberapa tempat di Korea. Lokasi-lokasi drama Korea menjadi alasan pemilihan objek wisata jika berkunjung ke Korea. Pemerintah Korea yang menyadari hal itu, memfasilitasi tempat-tempat yang digunakan sebagai pembuatan drama menjadi objek wisata di Korea. Adapun beberapa lokasi-lokasi yang dijadikan objek wisata ialah: Nami Island, Dae Jang Geum Theme Park, Pulau Jeju, Petite France, Seoul Color Park, Maiim Vision, Namsan Seoul Tower, Istana Changdeokgung, dan Sungai Han.

Sebenarnya, jauh sebelum masuknya budaya populer Korea ke Indonesia, Korea sudah memiliki hubungan dengan Indonesia sejak
September 1973. Namun setelah terlihatnya penyebaran K-Drama dan pemerintah Korea menyadari bahwa Korean wave bisa dijadikan alat penyebaran budaya Korea, maka kerjasama kebudayaan Indonesia dan Korea secara resmi baru berlangsung pada Agustus 2007.

Korea Selatan melakukan komunikasi ke negara lain menggunakan budayanya melalui Korean Wave (sebutan untuk budaya populer yang tersebar di luar Korea), untuk mengubah citranya di dunia. Hal yang dilakukan oleh Korea Selatan melalui Korean wave ini dilakukan juga ke Indonesia. Indonesia dan Korea Selatan melakukan kerjasama pada bidang kebudayaan.

Kerjasama kebudayaan dimulai pada Agustus 2007 secara resmi atas nama kedutaan besar, lalu pada Mei 2008 terjadi pertemuan pertama komite kebudayaan sebagai pondasi awal yang kuat dalam pertukaran kebudayaan. Ratifikasi Persetujuan Kerjasama Kebudayaan dengan Korea Selatan ditandatangani pada tahun 2000. Memorandum of Understanding (MoU) di bidang kepariwisataan antara kedua negara juga telah ditandatangani tahun 2006 sebagai tindak lanjut dari kerjasama bidang kebudayaan tersebut, pada tanggal 14-15 Mei 2008 di Yogyakarta diadakan the First Cultural Committee Meeting Indonesia-Korea Selatan. Pada tahun 2011, dengan pertimbangan sebagai penerapan lanjut pertukaran budaya antara Indonesia dan Korea selatan maka dibangunlah 
Korean Cultural Center Indonesia atau Pusat Kebudayaan Korea di Jalan Sudirman, Jakarta (www.id.korean-culture.org).

Korea Selatan mengambil langkah menyebarkan budayanya ke negara lain sebagai salah satu kekuatan negaranya yang bertujuan untuk memberikan pengaruh ke negara di luar Korea Selatan. Perkembangan perekonomian Korea Selatan salah satunya ialah karena perkembangan dari sektor kebudayaannya, yaitu munculnya Korean wave. Pada Desember 2010, CNN bahkan menyebut Korea Selatan sebagai Hollywood of the East, di mana Korea Selatan menghasilkan jutaan penggemar atas produk-produknya di Asia (Department Global Communication and Contents Division, 2012)

Komunikasi antar budaya yang dilakukan antara Indonesia dan Korea Selatan terlihat dari serangkaian kegiatan pameran kebudayaan yang dilakukan sejak tahun 2009. Awalnya pagelaran ini bernama dengan nama Korean Culture Week. Pagelaran kebudayaan ini diselenggarakan oleh Kedutaan Besar Republik Korea di Indonesia untuk memperkuat hubungan bilateral di bidang sosial-budaya. Duta Besar Republik Korea untuk Indonesia, Kim Ho Young membuka Korean Culture Week yang diselenggarakan dari tanggal 9-18 Oktober 2009 di Jakarta. Tujuan acara ini ialah untuk memperkenalkan budaya Korea, di mana terdapat penampilan budaya asli Korea yang telah dikembangkan dalam 5.000 tahun. Karena acara ini selain bertujuan utuk memperkenalkan budaya Korea, juga untuk menjalin hubungan kerjasama dalam bidang budaya, ada pula pertunjukan kesenian yang ditampilkan oleh orang Indonesia (Eka, 2009).

Tidak berhenti hanya sampai tahun 2009 , pagelaran budaya antara Korea Selatan dan Indonesia diadakan lagi pada tahun 2010, namun dengan nama Korea Indonesia Week. Terdapat pagelaran busana dengan pakaian tradisional Indonesia, Batik serta pakaian tradisional Korea, Hanbok. Selain itu, pada Korea Indonesia Week 2010 terdapat Korea Indonesia Friendship Festival yang menampilkan musisi Indonesia dan salah satu grup ternama dari Korea, SHINee (Arirang, 2010).

Berdasarkan antusiasme pengunjung yang datang mulai dari Korean Culture Week di tahun 2009, sampai berganti nama menjadi Korea Indonesia Week di tahun 2010, maka pada tahun 2011 kembali diadakan Korea Indonesia Weekdari 28 September hingga 3 Oktober 2011. Semenjak dibentuknya Korean Cultural Center Indonesia, maka acara Korea Indonesia Week pada tahun 2011 diselenggarakan oleh Kedutaan Besar Korea untuk Indonesia dengan kerja sama dari Korean Cultural Center Indonesia.

Ambassador Korea Selatan untuk Indonesia, Kim Young Sun mengatakan bahwa dengan memahami budaya, maka akan lebih 
memperkuat hubungan kerja sama antara kedua negara, yaitu Indonesia dan Korea Selatan. Pada tahun Korea Indonesia Week tahun 2011, terdapat Kompetisi Junior Taekwondo Nasional, di mana peserta yang lolos seleksi dari 33 provinsi di Indonesia bisa melanjutkan kompetisi untuk memenangkan Korean Ambassador Cup (Jeong, 2012).

Berbagai macam umur, menghadiri acara Korea Indonesia Week yang diselenggarakan di Main Atrium Mall Taman Anggrek, Jakarta dari 3 Oktober - 7 Oktober 2012. Sama seperti tahun-tahun sebelumnya, kegiatan tahunan yang diadakan oleh Kedutaan Besar Korea untuk Indonesia dan Korean Cultural Center Indonesia ini meliputi festival makanan, kompetisi K-Pop, pertunjukan film Korea, namun kali ini terdapat juga pertunjukan spesial yang diselenggarakannya di Nusa Indah Theatre Balai Kartini pada 4 Oktotober 2012. Pertunjukan khusus itu menampilkan pertunjukan tari tradisional, modern, dari Korea Selatan, dan drum dancing performance serta traditional percussion (Jeong, 2012).

K-Drama memiliki peranan yang cukup penting atas Korean wave di Indonesia. Di mana hal-hal tersebut dapat terlihat pada dampak K-Drama di Indonesia, seperti kemunculan komunitas-komunitas pecinta K-Drama, hadirnya situs dari Indonesia yang menyajikan informasi seputar Korea, bahkan hingga maraknya acara-acara yang mengundang aktor, penyanyi, idola-idola Korea ke Indonesia.

Selain itu terlihat juga imitasi produk budaya populer Korea Selatan paa produk budaya populer di Indonesia seperti kemunculan boyband girlband Indonesia yang berkiblatkan Korea. Namun tidak hanya pada konsep penyanyi, style Korea pun juga menjadi trend di Indonesia. Bahkan production house membuat sinetron yang diambil dari K-Drama.

\section{SIMPULAN}

Peranan K-Drama terhadap penyebaran Korean Wave di Indonesia, seperti dijelaskan di atas, memiliki peran yang signifikan. Melalui kekuatan K-Drama yang hadir di Indonesia pada waktu yang tepat, menawarkan cerita dengan alur cinderella story yang menarik bagi masyarakat Indonesia, juga secara detail menggambarkan budaya khas Korea mulai dari fashion, kuliner hingga teknologi, membuat Korean Wave di Indonesia semakin populer dan berkembang.

Korean Wave sendiri menjadi soft power Korea Selatan melalui budaya populernya yang diekspor ke berbagai negara dalam bentuk K-Drama, K-Pop, K-Style, kuliner dan teknologi. Melalui nilai-nilai yang terdapat dalam pembuatan budaya populer, terutama drama, Korea memadukan unsur modern dalam hal ini teknologi dengan tradisi dan nilai-nilai 
kekeluargaan. Korean wave di Indonesia sendiri ditandai dengan maraknya kemunculan kuliner khas Korea, sinetron adaptasi cerita K-Drama, fashion khas Korea, hingga tujuan wisata tempat pembuatan K-Drama.

\section{DAFTAR PUSTAKA}

Abdullah,A., Mahameruaji, J. N., \& Rosfiantika, E. (2018). "Si doel anak sekolahan", sinetron Indonesia paling fenomenal (tinjauan ilmu komunikasi atas sinetron si doel anak sekolahan). ProTVF: Jurnal Kajian Televisi Dan Film, 2(2), 209-219. https://doi.org/10.24198/ptvf.v2i2.20822

Arirang. (2010). Korea-Indonesia Friendship Sharing Concert. Retrieved May 30, 2019, from Arirang website: http://www.arirang. com/Tv2/TVCommon_NoStaff_Archive. asp?Prog_Code=TVCR0108\&MENU_ CODE $=100136 \&$ view_seq $=3206$

Chung, A. (2011). K-Drama: A New TV Genre with Global Appeal (Korean Culture Book 3). Seoul: Korean Culture and Information Service.

Department Global Communication and Contents Division. (2012). Hallyu (Korean Wave): Korea.net: The official website of the Republic of Korea. Retrieved May 30, 2019, from korea.net website: http://www. korea.net/AboutKorea/Culture-and-theArts/Hallyu

Eka. (2009). Korean Culture Week in Jakarta.
Retrieved September 5, 2012, from koreaindo.net website: http://koreanindo. net/2009/10/10/korean-culture-week-injakarta

Gemiharto, I., Abdullah, A., \& Puspitasari, L. (2017). Kajian kritis tayangan televisi favorit kelas menengah perkotaan (studi kasus tayangan televisi favorit kelompok masyarakat kelas menengah di Kota Bandung, Provinsi Jawa Barat). ProTVF: Jurnal Kajian Televisi Dan Film, 1(1), 13-29. https://doi.org/10.24198/ptvf. v1i1.13329

Jeong, Y. (2012). “Hallyu” Sweeps Korean Festival into Town. Retrieved October 19, 2012, from The Jakarta Post website: http:// thejakartapost.com/news/2012/10/09/ hallyu-sweeps-korean-festival-town.html

Nugroho, S. A. (2011). Hallyu di Indonesia: selama dekade pertama di abad ke-21. in m. Syamsudin (ed.), sejarah Korea menuju masyarakat modern: beberapa peristiwa penting. Yogyakarta: INAKOS.

Rakhmat, J. (2012). Metode penelitian komunikasi: dilengkapi contoh analisis statistik. Bandung: Remaja Rosdakarya.

Shim,D.(2006).Hybridity and the Rise ofKorean Popular Culture in Asia. Media, Culture and Society, Vol. 28, pp. 25-44. https://doi. org/10.1177/0163443706059278

Sjamsuddin, H. (2007). Metodologi sejarah. Bandung: Historia Utama Press.

Storey, J. (2006). Cultural studies dan kajian budaya pop. Yogyakarta: Jalasutra. 